\title{
A Mechanistic Study of the H/D Exchange Reactions of Protonated Arginine and Arginine-Containing Di- and Tripeptides
}

\author{
Yiqun Huang, Joe A. Marini, John A. McLean, ${ }^{*}$ Shane E. Tichy, \\ and David H. Russell \\ Department of Chemistry, The Laboratory for Biological Mass Spectrometry, Texas A\&M University, College \\ Station, Texas, USA
}

\begin{abstract}
The gas-phase H/D exchange reactions of arginine $(\mathbf{R})$ and arginine-containing di- and tri-peptide (gly-arg (GR), arg-gly (RG), gly-gly-arg (GGR), gly-arg-gly (GRG) and arg-gly-gly (RGG)) $[\mathrm{M}+\mathrm{H}]^{+}$ions with deuterated ammonia $\left(\mathrm{ND}_{3}\right)$ were investigated by using Fourier-transform ion cyclotron resonance mass spectrometry (FT-ICR), ion mobility-mass spectrometry (IM-MS), ab initio and density functional theory-based molecular orbital calculations and molecular modeling. Three exchanges are observed for arginine and argininecontaining tri-peptide $[\mathrm{M}+\mathrm{H}]^{+}$ions, whereas the di-peptide $[\mathrm{M}+\mathrm{H}]^{+}$ions undergo a single $\mathrm{H} / \mathrm{D}$ exchange. In addition, $\mathrm{C}$-terminal methylation blocks $\mathrm{H} / \mathrm{D}$ exchange of arginine and the arginine-containing peptide $[\mathrm{M}+\mathrm{H}]^{+}$ions, and a single $\mathrm{H} / \mathrm{D}$ exchange is observed for $\mathrm{N}$-terminal acetylated arginine $[\mathrm{M}+\mathrm{H}]^{+}$ions. A general mechanism for $\mathrm{H} / \mathrm{D}$ exchange involving a collision complex that is best described as a "solvated salt-bridge" structure is proposed. (J Am Soc Mass Spectrom 2009, 20, 2049-2057) (c) 2009 American Society for Mass Spectrometry
\end{abstract}

$\mathrm{H}$ ydrogen/deuterium (H/D) exchange reactions are frequently used to investigate the conformationrelated properties of solution-phase peptides and proteins. Although $\mathrm{H} / \mathrm{D}$ exchange reagents can access all labile hydrogen atoms of small peptides, the accessibility of exchange reagents toward labile hydrogen sites of larger peptides and proteins is conformation dependent [1], thus the rate of $H / D$ exchange reactions and the number of hydrogen atoms exchanged can be used as a structural probe [2]. H/D exchange and mass spectrometry can be combined to study both gas-phase and solutionphase H/D exchange reactions [3-9], and the kinetics of $\mathrm{H} / \mathrm{D}$ exchange can be utilized to infer the presence of distinct conformations of both solution-phase [10-12] and gas-phase peptide and protein ions [13]. For example, McLuckey et al. studied the gas-phase H/D exchange of bradykinin $[\mathrm{M}+\mathrm{H}]^{+}$ions (amino acid sequence RPPGFSPFR) with DI and $\mathrm{D}_{2} \mathrm{O}$, and they interpreted the observed bimodal distributions of product ions as evidence for two non-interconverting ion conformations having different reactivities toward deuterating reagents [14]. On the other hand, Freitas and Marshall invoked the presence of zwitterions to explain the $\mathrm{H} / \mathrm{D}$ exchange reactions of bradykinin with $\mathrm{D}_{2} \mathrm{O}$

Address reprint requests to Dr. D. H. Russell, Department of Chemistry, The laboratory for Biological Mass Spectrometry, Texas A\&M University, 3255 TAMU, College Station, TX 77843, USA. E-mail: russell@mail. chem.tamu.edu

* Current address: Department of Chemistry, Vanderbilt University, Nashville, TN 37215, USA.
[15]. Valentine and Clemmer used ion mobility-mass spectrometry to examine the conformation dependence of $H / D$ exchange reactions, and suggested that ion conformation has a significant effect on $\mathrm{H} / \mathrm{D}$ exchange $[16,17]$.

Compared with the intensive investigations carried out on the conformational characterization of peptides and proteins using solution-phase H/D exchange reaction chemistry, the corresponding gas-phase studies are much less comprehensive. The key question regarding gas-phase H/D exchange is: does the "solvent molecule," i.e., H/D exchange reagent, sample the entire "available surface area" of the peptide/protein ion, or is H/D exchange limited by other factors? For example, are all solution phase labile hydrogen atoms exchangeable in the gas phase and are the reactivities of all exchangeable hydrogen atoms similar? Dookeran and Harrison studied the H/D exchange reactions of 18 naturally occurring amino acids and selected di- and tripeptides with $\mathrm{ND}_{3}$, and reported that amino acid $[\mathrm{M}+\mathrm{H}]^{+}$ions containing hydroxyl, carboxyl, and amine side chains exchange all labile hydrogen atoms, whereas the side-chain hydrogen atoms of glutamine, asparagine, and histidine $[\mathrm{M}+\mathrm{H}]^{+}$ions exchange less readily, and tyrosine and arginine $[\mathrm{M}+\mathrm{H}]^{+}$ions do not undergo significant exchange [18]. In a separate study, Lebrilla et al. found that the carboxylic acid group of glycine and aliphatic amino acid $[\mathrm{M}+\mathrm{H}]^{+}$ions (alanine, valine, leucine, isoleucine, and proline) undergo $\mathrm{H} / \mathrm{D}$ exchange three to 10 times faster than the $\mathrm{N}$ - 
terminal amino group when reacted with $\mathrm{CH}_{3} \mathrm{OD}$ [19]. Kovačevič et al. observed unusual reactivity of histidine $[\mathrm{M}+\mathrm{H}]^{+}$ions with $\mathrm{CD}_{3} \mathrm{OD}$ and $\mathrm{D}_{2} \mathrm{O}$ : (1) three equivalent fast exchanges, (2) one nonequivalent fast exchange, and (3) one extremely slow exchange, which they assigned to the protonated amino group, the carboxylic acid group and the distal imidazole nitrogen, respectively [20].

Differences in gas-phase H/D exchange reactions may be the result of isolated charge sites that are stabilized by intramolecular interactions, whereas charge sites of solution-phase ions are stabilized by solvation. Issues related to how intramolecular interactions influence $\mathrm{H} / \mathrm{D}$ exchange chemistry has been noted in the previous mechanistic studies of $H / D$ reactions. For example, Beauchamp and coworkers considered several possible mechanisms for $\mathrm{H} / \mathrm{D}$ exchange reactions of glycine oligomer $\left[\mathrm{Gly}_{n}+\mathrm{H}\right]^{+}$ions with a series of exchange reagents, $\mathrm{D}_{2} \mathrm{O}, \mathrm{CD}_{3} \mathrm{OD}, \mathrm{CD}_{3} \mathrm{COOD}$, and $\mathrm{ND}_{3}$, and found that the rate and extent of $H / D$ exchange depends on peptide structure and the gas-phase proton affinity (PA) difference between the deuterating reagent and the peptide functional group [21, 22]. On the basis of semiempirical molecular orbital calculations, they proposed five different $\mathrm{H} / \mathrm{D}$ exchange reaction mechanisms. For example, protonation of Gly $\mathrm{n}_{\mathrm{n}}$ usually occurs at the N-terminus, thus N-terminal hydrogens of $\left[\mathrm{Gly}_{\mathrm{n}}+\mathrm{H}\right]^{+}$ ions exchange with $\mathrm{ND}_{3}(\mathrm{PA}=204 \mathrm{kcal} / \mathrm{mol}$ [23] $)$ via an onium ion mechanism, which was also supported by density functional theory studies [24]. On the other hand, $\mathrm{H} / \mathrm{D}$ exchange of $\left[\mathrm{Gly}_{\mathrm{n}}+\mathrm{H}\right]^{+}$ions with $\mathrm{D}_{2} \mathrm{O}$ $(\mathrm{PA}=165 \mathrm{kcal} / \mathrm{mol}$ [23]), a reaction associated with a highly endothermic deprotonation step, occurs by a relay mechanism, and $H / D$ exchanges occurring at either the carboxyl group or amide bonds can be explained by salt-bridge or tautomer mechanisms. In addition, $\mathrm{H} / \mathrm{D}$ exchange of $\left[\mathrm{Gly}_{\mathrm{n}}+\mathrm{Na}\right]^{+}$ions with $\mathrm{ND}_{3}$ occurs by an onium ion mechanism involving shuttling of the ammonium ion between $\mathrm{C}$ - and N-termini of a zwitterionic intermediate [25a]. Although that study focused on glycine $[\mathrm{M}+\mathrm{Na}]^{+}$ion oligomers, the idea that a fixed charge, $\mathrm{Na}^{+}$, can stabilize a zwitterionic intermediate can be extended to peptide ions containing basic (arginine, lysine, and histidine) amino acid residues. For instance, Geller and Lifshitz investigated the $\mathrm{H} / \mathrm{D}$ exchange of arginine monomers and dimer [M + $\mathrm{H}]^{+}$ions with $\mathrm{ND}_{3}$, and suggested that it might be possible for ammonia to stabilize the zwitterionic structure of arginine by forming a salt-bridge complex [25b]. Wyttenbach and Bowers also suggested that H/D exchange of bradykinin with $\mathrm{D}_{2} \mathrm{O}$ occurs via a relay mechanism [26], and they suggested that a basic site must be in the vicinity of the protonation site, and both sites must be accessible to $\mathrm{D}_{2} \mathrm{O}$. Clearly, the presence of basic amino acid residues (arginine, lysine, and histidine) profoundly influences $H / D$ exchange chemistry of $[\mathrm{M}+\mathrm{H}]^{+}$ions because protonation on the basic side chain forms a very stable ion, which, based on differences in proton affinity [21, 22] (PA of arginine is 251.2 $\mathrm{kcal} / \mathrm{mol}$ compared with $211.9 \mathrm{kcal} / \mathrm{mol}$ for glycine), should not react with $\mathrm{NH}_{3}$ [23]. Bowers and Wysocki examined the $H / D$ exchange reactions of argininecontaining pentapeptide $[\mathrm{M}+\mathrm{H}]^{+}$ions with $\mathrm{D}_{2} \mathrm{O}$, and suggested that $\mathrm{H} / \mathrm{D}$ exchange occurs by a relay mechanism and that the formation of a charge solvated intermediate complex is crucial for the occurrence of H/D exchange [27].

It is also important to consider how the structure of the peptide ion before and following interaction with the "solvent molecule" might affect the H/D exchange process. Although solution-phase peptides favor zwitterionic structures because the separated charges can be stabilized by solvation, non-zwitterionic structures are favored for gas-phase peptide ions, especially for the nonpolar amino acids. For basic amino acids and peptides containing basic residues the preference for zwitterionic forms has been studied by several groups and conflicting data presented [28-32]. For example, the experimental results obtained from blackbody infrared dissociation (BIRD) were interpreted as evidence for charge-separated, stable salt-bridge structures for a protonated arginine dimer [33], while IR cavity ringdown spectroscopy study suggested a non-zwitterionic structure for arginine [34]. Julian and coworkers have also examined structures of amino acid clusters and presented convincing data that multimers of arginine favor zwitterionic structures which are stabilized by intramolecular charge solvation, i.e., formation of salt-bridges [35].

The paper presents a systematic investigation of the H/D exchange reactions of arginine and argininecontaining di- and tripeptide $[\mathrm{M}+\mathrm{H}]^{+}$ions with $\mathrm{ND}_{3}$, with specific emphasis on the influence of intramolecular interactions on rates of reaction and extent of deuterium incorporation. The intramolecular interactions, specifically charge solvation, determine the structure of the ion, which directly affects solvent accessibility. We show that hydrogen atoms that are normally considered labile in solution are nonlabile in the gasphase, i.e., noninteracting with the solvent molecule, thus H/D exchange of gas-phase ions reflect "solvent accessibility" as well as intramolecular interactions, which stabilize key solute-solvent interactions.

\section{Experimental}

The H/D exchange experiments were carried out using a two-section ion cell FT-ICR mass spectrometer (3-tesla Oxford horizontal bore super-conducting magnet) described elsewhere [36]. The FT-ICR instrument is equipped with a $355 \mathrm{~nm} \mathrm{Nd:YAG} \mathrm{laser} \mathrm{for} \mathrm{laser} \mathrm{desorp-}$ tion ionization (LDI) of the sample. The two-section ion cell is differentially pumped (base pressure at $5 \times 10^{-9}$ torr) by two Alcatel (Hingham, MA, USA) oil diffusion pumps, each backed with a mechanical pump. Ion gauges are installed in each vacuum chamber, and the ion gauges were calibrated for the neutral reagent and for the pressure gradient between the cell and the 
ion gauge [37]. Volatile samples are admitted to the vacuum system using Varian (Lexington, MA, USA) variable leak valves (part number 9515106).

The FT-ICR experiments were carried out using standard pulse sequences. That is, residual ions were removed from both regions of the two-section ion cell by applying a $50 \mathrm{~ms}$ quench pulse $(+10 \mathrm{~V}$ applied to the end trap plates with the conductance plate held at $0 \mathrm{~V}$ ). Following the quench pulse (delayed by $\sim 1 \mathrm{~ms}$ ) a new population of ions were produced using a single $17 \mathrm{~ns}$ pulse from the $355 \mathrm{~nm}$ Nd:YAG laser. The laser output was focused to a spherical spot of $\sim 200 \mu \mathrm{m}^{2}$ using standard fused silica lens. Arginine or arginine-containing peptide $[\mathrm{M}+\mathrm{H}]^{+}$ ions generated by MALDI were isolated using standard SWIFT excitation pulses [38], and the mass-selected ions were then transferred to the analyzer cell and allowed to react with $\mathrm{ND}_{3}$ for times ranging from $5 \mathrm{~ms}$ to $15 \mathrm{~min}$ at $1 \times 10^{-8}$ to $2 \times 10^{-7}$ torr, followed by product ion excitation and detection. The ion temporal profiles were used to determine the kinetics of H/D exchange. For example, the second-order rate constant $\left(\mathrm{k}_{\exp }\right)$ for the reactant ion depletion was obtained from a semilogarithmic plot of reactant ion abundance versus reaction time. A parameterized trajectory theory [39] was used to estimate the collision rate constants $\left(\mathrm{k}_{\mathrm{coll}}\right)$. Reaction efficiencies $\left(\mathrm{k}_{\text {exp }} / \mathrm{k}_{\text {coll }}\right)$ contained in column 1 of Table 1 are the average values obtained from multiple experiments. Relative reaction rates $\left(\mathrm{k}^{\prime}{ }_{1}-\mathrm{k}^{\prime}{ }_{4}\right.$; also listed in Table 1) for the product ions formed by exchange were obtained by numerically fitting the exact solutions of the differential kinetics equations (assuming pseudofirst-order approximations) to the ion temporal profiles. Fitting procedures are preferred over experimentally measured kinetics data owing to low confidence values in the measured rates for slow reactions, i.e.,

Table 1. Reaction efficiencies and the numerically fitted parameters describing each exchange steps

\begin{tabular}{lcllcc}
\hline & $\begin{array}{c}\text { Reaction } \\
\text { efficiencies }\end{array}$ & \multicolumn{5}{c}{ Numerically fitted parameters $\left(\mathrm{s}^{-1}\right)$} \\
\cline { 3 - 7 }$[\mathrm{MH}]^{+}$ & $(100 \%)$ & \multicolumn{1}{c}{$\mathrm{k}_{1}{ }^{\prime}$} & \multicolumn{1}{c}{$\mathrm{k}_{2}{ }^{\prime}$} & $\mathrm{k}_{3}{ }^{\prime}$ & $\mathrm{k}_{4}{ }^{\prime}$ \\
\hline \hline Arginine & 24 & 0.66 & 0.049 & 0.025 & 0.0065 \\
RG & 7.4 & 0.30 & 0.00017 & - & - \\
GR & 17 & 1.0 & 0.00028 & - & - \\
RGG & 27 & 1.0 & 0.013 & 0.011 & 0.0085 \\
GRG & 5.9 & 0.26 & 0.038 & 0.019 & 0.0020 \\
GGR & 28 & 1.5 & 0.035 & 0.017 & 0.00020 \\
arg-OMe & 0.01 & 0.00040 & - & - & - \\
RG-OMe & 0.04 & 0.00020 & - & - & - \\
GR-OMe & 0.005 & 0.00035 & - & - & - \\
RGG-OMe & 0.0025 & 0.00010 & - & - & - \\
GRG-OMe & 0.035 & 0.0014 & - & - & - \\
GGR-OMe & 0.033 & 0.0013 & - & - & - \\
\hline
\end{tabular}

Measured rate constant for decay $\left(\mathrm{k}_{\text {exp }}\right)$ of the arginine $[\mathrm{M}+\mathrm{H}]^{+}$ion to form $[\mathrm{M}+\mathrm{D}]^{+}$is $3.7 \times 10^{-10} \mathrm{~cm}^{3}$ molecule ${ }^{-1} \mathrm{~s}^{-1}$, and $\mathrm{k}_{\text {coll }}$ is estimated to be $1.6 \times 10^{-9} \mathrm{~cm}^{3}$ molecule ${ }^{-1} \mathrm{~s}^{-1}$. The rate constants (in units of $\mathrm{cm}^{3}$ molecule ${ }^{-1} \mathrm{~s}^{-1}$ ) for RG, GR, RGG, GRG, and GGR are $1.5 \times 10^{-10}, 2.6 \times$ $10^{-10}, 4.2 \times 10^{-10}, 0.9 \times 10^{-10}, 4.3 \times 10^{-10}$, respectively. A value for $k_{\text {coll }}$ of $1.6 \times 10^{-9} \mathrm{~cm}^{3}$ molecule ${ }^{-1} \mathrm{~s}^{-1}$ was used for all the ions owing to the insignificant errors introduced by variations in the reduced mass $(\mu)$. reactions having rate constants of less than $1 \times 10^{-10}$ $\mathrm{cm}^{3}$ molecule ${ }^{-1} \mathrm{~s}^{-1}$.

The amino acids and peptides used for these studies were ionized by MALDI using a binary matrix $\left(2^{\prime}, 4^{\prime}, 6-\right.$ trihydroxyacetophenone monohydrate (THAP) and Dfructose, obtained from Sigma (St. Louis, MO, USA) sample preparation method. Fructose was used to increase the MALDI efficiency [40]. Approximately 10 $\mathrm{mM}$ solutions of the amino acid or peptide samples (Bachem, King of Prussia, PA, USA) as well as their C-terminal methylated derivatives (synthesized using the procedure described previously [41]) were prepared by dissolving the samples in deionized water (containing $0.1 \%$ acetic acid by volume). The solutions were then mixed with an appropriate volume of $500 \mathrm{mM}$ D-fructose and $250 \mathrm{mM}$ MALDI matrix solutions to obtain a D-fructose/matrix/peptide mixture with the molar ratio of 40:20:1. Successive $30 \mu \mathrm{L}$ aliquots of the mixture were applied to the MALDI sample plate until the surface was covered. The MALDI sample plate was introduced to the spectrometer using a direct-insertion solids probe.

Deuterated ammonia $\left(99.5 \% \mathrm{ND}_{3}\right.$; from Cambridge Isotope Laboratories, Inc., Andover, MA, USA) was introduced into the instrument by a Varian variable leak valve. The vacuum chamber was "primed" with $\mathrm{ND}_{3}\left(\mathrm{ND}_{3}\right.$ was leaked into the vacuum system at a pressure of $1 \times 10^{-6}$ torr) for at least $2 \mathrm{~h}$ before performing $H / D$ exchange experiments.

The H/D exchange reactions of acetylated peptides were measured by using a quadrupole ion trap (Finnigan LCQ DECA, Thermo Finnigan, Waltham, MA, USA) that has been modified for introduction of volatile gases using variable leak valves (Varian model 9515106). The $[\mathrm{M}+\mathrm{H}]^{+}$ions were formed by ESI and the abundances of product ions were measured at a fixed reaction time and pressure, thus no attempts were made to measure the kinetics of these reactions.

Ion mobility-mass spectrometry (IM-MS) measurements were carried out using a MALDI-ion mobilitytime of flight (MALDI-IM-TOF) mass spectrometer that has been previously described [42]. Collision crosssection measurements were performed using a drift cell pressure of 3.16 torr of He gas using field strengths corresponding to $\mathrm{E} / \mathrm{p}$ ratios of $25-40 \mathrm{~V} \mathrm{~cm}{ }^{-1} \mathrm{Torr}^{-1}$. MALDI was performed at $300 \mathrm{~Hz}$ using a frequencytripled (355 nm) Nd:YAG laser (Nanolase; JDS Uniphase, Milpitas, CA, USA). Data acquisition and extraction of collision cross section profiles were performed using custom software (Ionwerks, Inc., Houston, TX, USA). The structures of arginine and arginine-containing diand tripeptide $[\mathrm{M}+\mathrm{H}]^{+}$ions were obtained by using Insight II (Accelerys, San Diego, CA) and molecular dynamics simulation coupled with annealing using Cerius version 4.2 (Accelerys). For each annealing cycle, the different initial structures were heated and cooled in a stepwise manner, starting and ending at $300 \mathrm{~K}$ and peaking at $1000 \mathrm{~K}$ using temperature increments of $50 \mathrm{~K}$ and relaxation times of $0.1 \mathrm{ps}$. Each dynamic simulation 
step lasts 0.001 ps. After each annealing cycle, the peptide structures were optimized using CFF 1.02 force field. Annealing cycles were repeated 100 times for each given initial structures. For all the optimized geometries, only those with lowest steric energy were chosen to perform ab initio- and density functional theorybased molecular orbital calculations.

The potential energy surfaces for the proposed H/D exchange reaction pathways of arginine and argininecontaining di- and tripeptide $[\mathrm{M}+\mathrm{H}]^{+}$ions with $\mathrm{ND}_{3}$ were explored using $\mathrm{ab}$ initio and density functional theory-based molecular orbital calculations with the Gaussian 03 revision A.11 suite of programs [43, 44]. For arginine $[\mathrm{M}+\mathrm{H}]^{+}$ions, the enthalpy changes (exothermicities) for formation of ion-molecule complexes were determined directly at zero Kelvin by optimizing the geometries of the reactants, products, as well as ionmolecule intermediates, and calculating their corresponding electronic energies at the MP2/6-31+G(d,p) level of theory. All optimized geometries were verified to be real local minima by performing frequency analysis (no imaginary frequencies). The corresponding zero-point vibrational energies (ZPVE) were calculated at the same level of theory and used to correct the electronic energies (without scaling). The geometries and energies of transition states were determined by performing transition state calculations at the same level of theory. The transition states were also verified as true first-order saddle points along the correct reaction coordinate by frequency analysis (one imaginary frequency corresponding to the vibration along the reaction coordinate that leads to the decomposition of transition state into products). The potential energy surfaces for arginine-containing peptide $[\mathrm{M}+\mathrm{H}]^{+}$ions gly-arg (GR), arg-gly (RG), gly-gly-arg (GGR), gly-arggly (GRG), and arg-gly-gly (RGG) were investigated at the B3LYP/6-31G(d,p)//HF/3-21G(d,p) level of theory.

\section{Results and Discussion}

Our studies on the mechanism of H/D exchange of arginine and arginine-containing di- and tripeptide $[\mathrm{M}+\mathrm{H}]^{+}$ions began by considering plausible structures for the MALDI formed ions. We assumed that protonation occurred on the guanidine group owing to the high proton affinity $(\mathrm{PA}=251.2 \mathrm{kcal} / \mathrm{mol}$ ) for arginine [23], but we also considered whether the most stable structure of the $[\mathrm{M}+\mathrm{H}]^{+}$ion is a charge-solvated species, as suggested by Simon et al. [31], or zwitterionic species, as suggested by Strittmatter and Williams [28]. To address this question, we used a combination of collision cross-sections obtained by using ion mobility spectrometry (IMS) [45], molecular dynamics simulations, and molecular orbital calculations. The collision crosssection for $[\mathrm{GGR}+\mathrm{H}]^{+},[\mathrm{GRG}+\mathrm{H}]^{+}$, and $[\mathrm{RGG}+\mathrm{H}]^{+}$ ions, and the protonated methyl esters of the same three molecules are listed in Table 2. The positional isomers have measurably different collision cross-sections, which decrease in the order of $[\mathrm{GRG}+\mathrm{H}]^{+}>[\mathrm{GGR}+$
Table 2. The experimental and calculated collisional cross-sections of protonated arginine-containing di- and tri-peptides and their C-terminal methylated analogs

\begin{tabular}{lccc}
\hline & $\begin{array}{c}\text { Measured } \\
\text { cross-sections } \\
\left(\AA^{2}\right)\end{array}$ & $\begin{array}{c}\text { *Calculated }^{+} \\
\text {cross-sections } \\
\left(\AA^{2}\right)\end{array}$ & $\begin{array}{c}{ }^{*} \text { Calculated } \\
\text { cross-sections } \\
\left(\AA^{2}\right)\end{array}$ \\
\hline \hline GGR & 103.3 & 106.0 & 103.6 \\
GRG & 107.7 & 109.2 & 100.8 \\
RGG & 102 & 105.2 & 100.1 \\
GR & 91.5 & 94.0 & 90.2 \\
RG & 90.5 & 91.9 & 87.5 \\
GGROMe & 109.8 & 112.4 & $\mathrm{n} / \mathrm{a}$ \\
GRGOMe & 114.8 & 113.7 & $\mathrm{n} / \mathrm{a}$ \\
RGGOMe & 107.5 & 108.8 & $\mathrm{n} / \mathrm{a}$ \\
GROMe & 97.5 & 98.0 & $\mathrm{n} / \mathrm{a}$ \\
RGOMe & 96 & 96.8 & $\mathrm{n} / \mathrm{a}$ \\
\hline
\end{tabular}

*Assuming charge solvated canonical structures.

**Assuming zwitterionic structures.

$\mathrm{H}]^{+}>[\mathrm{RGG}+\mathrm{H}]^{+}$, and similar trends in collision cross-sections are observed for the methyl ester [M + $\mathrm{H}]^{+}$ions. A comparison of measured and calculated peak profiles suggests that the ion population consist of either a single conformation or a population of conformers having very similar collision cross-sections [46]. Note also that the collision cross-section for $[\mathrm{GR}+\mathrm{H}]^{+}$is larger than that for $[\mathrm{RG}+\mathrm{H}]^{+}$, and the methyl esters exhibit the same ordering. If the peptide ions were present as zwitterions, then we would expect some variation in the collision cross-sections for the peptide and methyl ester ions owing to a reduction in the interaction between charge sites [47, 48]. Our molecular dynamics simulation and molecular orbital calculations also suggest that charge-solvated species represent the most stable conformations of the [M + $\mathrm{H}^{+}$ions, which is consistent with Simon's studies [31]. Theoretical collision cross-sections for $[\mathrm{M}+\mathrm{H}]^{+}$ ions for arginine-containing di- and tripeptide and C-terminal methylated derivatives (see Table 2) were calculated by using Mobcal [49]. The theoretical crosssections of methylated species follow the trend $[\mathrm{GRGOMe}+\mathrm{H}]^{+}>$[GGROMe $\left.^{+\mathrm{H}}\right]^{+}>[\mathrm{RGGOMe}+$ $\mathrm{H}^{+}$, and $[\mathrm{GROMe}+\mathrm{H}]^{+}>[\mathrm{RGOMe}+\mathrm{H}]^{+}$, which agrees well with the experimentally determined ordering. The same trend was obtained for nonmethylated species, assuming canonical rather than zwitterionic structures, whereas cross-section ordering for zwitterionic tripeptide ions is $[\mathrm{GGR}+\mathrm{H}]^{+}>[\mathrm{GRG}+\mathrm{H}]^{+}>$ $[\mathrm{RGG}+\mathrm{H}]^{+}$. On the basis of these results, we will focus the remainder of our discussion on charge solvated, canonical structures.

Temporal plots for the reactant and product ions of $\mathrm{H} / \mathrm{D}$ exchange reactions for $[\mathrm{M}+\mathrm{H}]^{+}$ions of arginine, arginine methyl ester, and selected arginine-containing di- and tripeptides are contained in Figure 1, and temporal plots for the remaining ions investigated in this study are available as Supplemental Material, which can be found in the electronic version of this article. Although the $[\mathrm{M}+\mathrm{H}]^{+}$ions of arginine and 

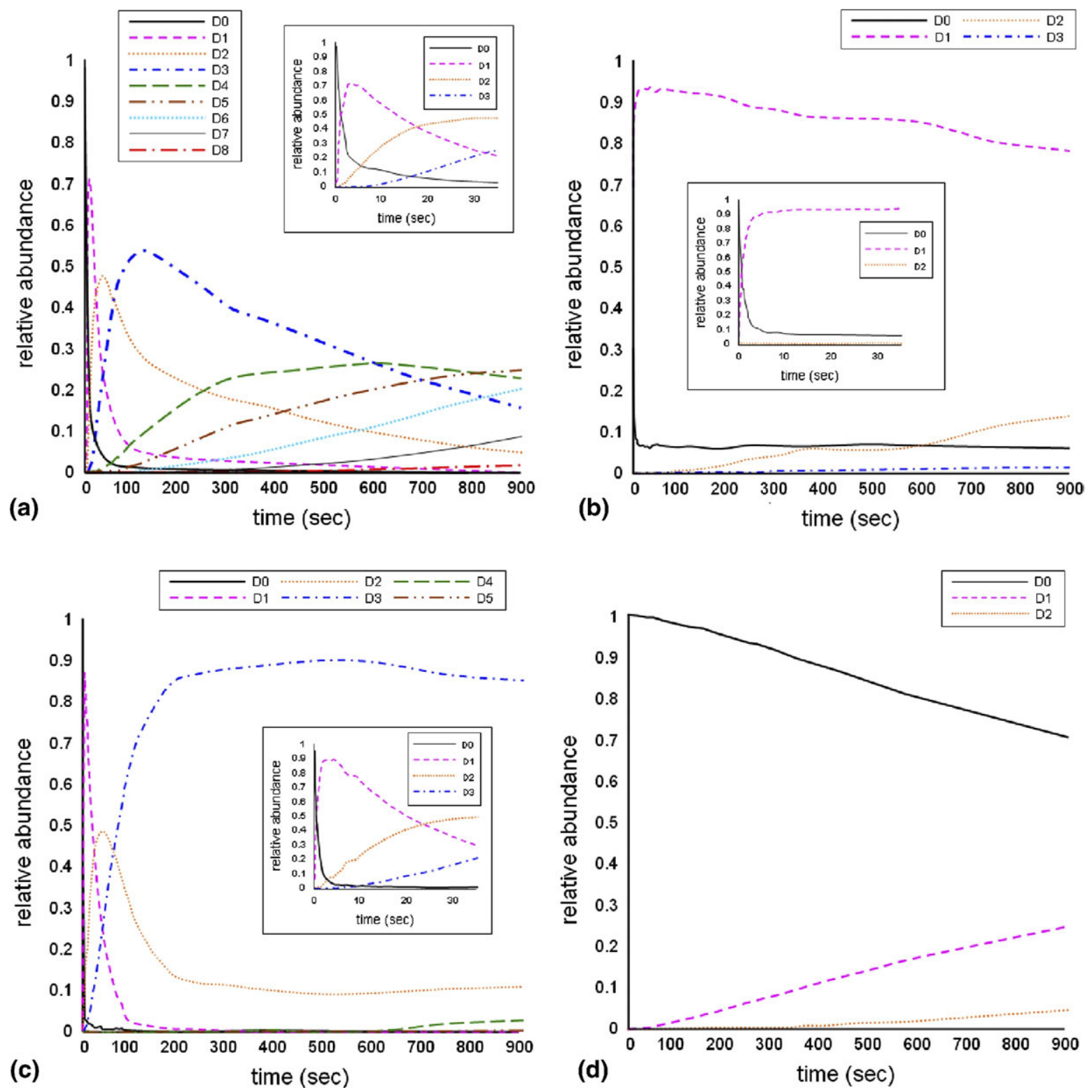

Figure 1. A plot of relative abundance of reactant and product ions for reaction of (a) arginine, (b) GR, (c) GGR, and (d) methylated arginine $[\mathrm{M}+\mathrm{H}]^{+}$ions when reacted with $\mathrm{ND}_{3}\left(\mathrm{ND}_{3}\right.$ pressure of $6.6 \times 10^{-8}$ torr).

arginine-containing di- and tripeptides contain eight, nine, and 10 labile hydrogen atoms, respectively, relatively few exchanges are observed. For example, reactions with $\mathrm{ND}_{3}$ over a period of $200 \mathrm{~s}$, which corresponds to 500-600 collisions, yield a single product ion for the dipeptide ions and a maximum of three exchanges for tripeptide ions. Note also that the reactions are relatively inefficient. Reaction efficiencies for reactant ions (see Table 1, column 2) are expressed as the ratio of $k_{\text {exp }} / k_{\text {coll }}$ (see Experimental section). In addition, using ion ejection techniques as described by Beauchamp et al., we do not find any evidence of multiple exchanges occurring in a single collision, thus apparently multiple $\mathrm{H} / \mathrm{D}$ exchanges occur as a result of consecutive ion-neutral collisions [21]. The assumption is also supported by the agreement between experimental and numerically fitted temporal profiles. It is also interesting to note that $\mathrm{C}$-terminal methylation of arginine and the di- and tri- arginine-containing peptides reduces the $H / D$ exchange reaction efficiency by a factor of $10^{3}$, and we only observe a single H/D exchange reaction for the N-terminal acetylated derivatives of arginine as well as the acetylated di- and tri- arginine-containing $[\mathrm{M}+\mathrm{H}]^{+}$ions.

In an effort to formulate a mechanism for $\mathrm{H} / \mathrm{D}$ exchange, we will focus our discussion on three independent observations: effects of (1) C-terminal methylation and (2) N-terminal acetylation on the observed 
H/D exchange reactions, and (3) the sequence dependence for H/D exchange. First, the large reduction in efficiency of H/D exchange for the methyl ester [M + $\mathrm{H}]^{+}$ions relative to the C-terminal acid ions suggests that the $-\mathrm{COOH}$ group is directly involved in the reaction. The fact that only a single $\mathrm{H} / \mathrm{D}$ exchange product ion is observed upon N-terminal acetylation is strong evidence that the $\mathrm{N}$-terminus also affects the $\mathrm{H} / \mathrm{D}$ exchange chemistry. On the basis of proton affinities and our structural assignments for the various $[\mathrm{M}+\mathrm{H}]^{+}$ions it seems unlikely that the ionizing proton is located on the $-\mathrm{COOH}$ group $(\mathrm{PA}=187.3$ $\mathrm{kcal} / \mathrm{mol}$ for $\mathrm{CH}_{3} \mathrm{COOH}$ [23]) compared with the guanidine group (PA $=251.2 \mathrm{kcal} / \mathrm{mol}$ for arginine [23]) or $\mathrm{N}$-terminus ( $\mathrm{PA}=211.9 \mathrm{kcal} / \mathrm{mol}$ for glycine [23]). That is, all the experimental data and results of energetic calculations suggest that the ionizing proton is located on the guanidine group. Owing to the large differences in PA of $\mathrm{ND}_{3}(204 \mathrm{kcal} / \mathrm{mol}$ [23] $)$ and the carboxylate anion ( $\mathrm{PA}=343.2 \mathrm{kcal} / \mathrm{mol}$ for $\mathrm{CH}_{3} \mathrm{COO}^{-}$anion [23]), $\mathrm{H} / \mathrm{D}$ exchange between $\mathrm{ND}_{3}$ and the $-\mathrm{COOH}$ group would not normally be energetically favorable. On the other hand, methylation of the C-terminus greatly reduces (by a factor of $\sim 10^{3}$ ) the $\mathrm{H} / \mathrm{D}$ exchange efficiency of arginine as well as the di- and tri- arginine-containing $[\mathrm{M}+\mathrm{H}]^{+}$ions, thus $\mathrm{H} / \mathrm{D}$ exchange must somehow be directly linked to the carboxylic acid group. It is also worth noting that arginine and arginine containing peptide $[\mathrm{M}+\mathrm{H}]^{+}$ions are unique in this regard. For example, we also examined the $\mathrm{H} / \mathrm{D}$ exchange ionmolecule reaction of $[\mathrm{M}+\mathrm{H}]^{+}$ions of histidine, lysine, and the histidine and lysine containing di- and tripeptides, all of which exhibit temporal plots that are very different from the arginine $[\mathrm{M}+\mathrm{H}]^{+}$ions. Specifically, the histidine and lysine $[\mathrm{M}+\mathrm{H}]^{+}$ions react very efficiently $\left(\mathrm{k}_{\text {exp }} / \mathrm{k}_{\text {coll }}>0.75\right)$ and undergo complete exchange of all labile hydrogen atoms [50].

Secondly, we compared the sequence dependence of the $H / D$ exchange reaction. The numbers of $H / D$ exchanges observed does not show significant sequence dependence, i.e., the numbers of exchanges for RG and $\mathrm{GR}[\mathrm{M}+\mathrm{H}]^{+}$ions are very similar and the same is true for RGG, GRG, GGR $[\mathrm{M}+\mathrm{H}]^{+}$ions. On the other hand, the $H / D$ exchange efficiencies $\left(k_{\exp } / k_{\text {coll }}\right)$ are sequence dependent (Table 1). In the following sections we will limit our discussion to the first $\mathrm{H} / \mathrm{D}$ exchange reaction because reactive ion-neutral encounters, which do not yield $\mathrm{H} / \mathrm{D}$ exchange product ions, may play an important role at longer reaction times. That is, possibly collisions between the $[\mathrm{M}+\mathrm{H}]^{+}$ion and solvent molecule occur but do not result in H/D product ions; however, such collisions could result in a structural change (interconversion between conical and zwitterionic forms) of the reactant ion via a shuttling mechanism without $\mathrm{H} / \mathrm{D}$ exchange [27].

The first H/D exchange reaction for arginine $[\mathrm{M}+$ $\mathrm{H}]^{+}$ions is relatively efficient $\left(\mathrm{k}_{\exp } / \mathrm{k}_{\text {coll }}=24 \%\right)$, as are the reactions of GR $(17 \%)$, RGG $(27 \%)$, and GGR $(28 \%)$ $[\mathrm{M}+\mathrm{H}]^{+}$ions. Note the reaction efficiencies of RG (7\%) and GRG $(6 \%)[\mathrm{M}+\mathrm{H}]^{+}$ions. These differences in reaction efficiencies will be rationalized on the basis of ion structures and the mechanism described below. Close inspection of the temporal plots suggests that decay of initially formed $[\mathrm{M}+\mathrm{H}]^{+}$ion may be biexponential; however, this is probably the result of a small amount of back exchange (with residual $\mathrm{NH}_{\mathrm{x}} \mathrm{D}_{\mathrm{y}}$ or other background gases, possibly $\mathrm{H}_{2} \mathrm{O}$ ) from the $[\mathrm{M}+$ $\mathrm{D}^{+}$ion formed by the exchange of a single $\mathrm{H}$ atom.

On the basis of experimental and extensive computational studies, we derived a potential energy surface

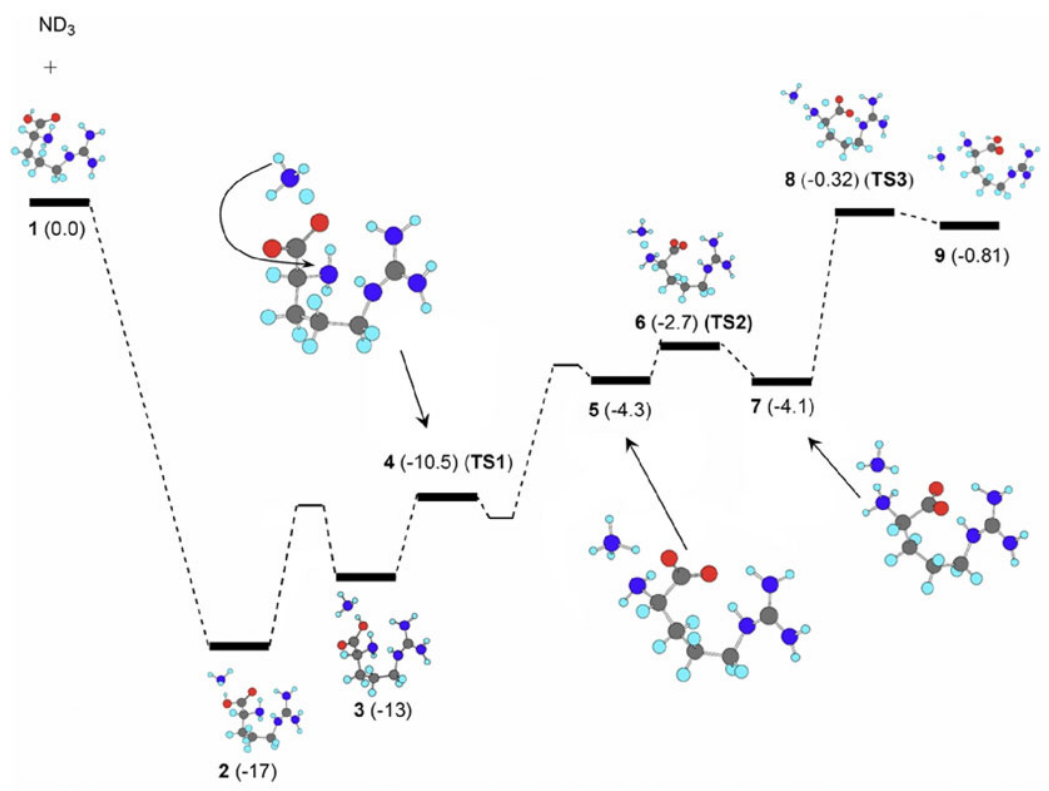

Figure 2. The potential energy surface for $\mathrm{H} / \mathrm{D}$ exchange of protonated arginine with $\mathrm{ND}_{3}$, as calculated at the MP2/6-31+G(d,p) level of theory. The numbers given in brackets are in $\mathrm{kcal} / \mathrm{mol}$. 
for $\mathrm{H} / \mathrm{D}$ exchange of arginine ions $[\mathrm{M}+\mathrm{H}]^{+}$(see Figure 2). The reaction pathway is initiated as the $[\mathrm{M}+$ $\mathrm{H}]^{+}$ion approaches $\mathrm{ND}_{3}$ to form the ion-neutral Complex 2. It is interesting to note that the first transition state TS1(4) cannot be achieved directly via the lowest energy collision Complex 2 unless the carboxylic acid group undergoes a rotation to form Complex 3. Although the lowest energy conformation does not always position the carboxylic acid group in such a manner as to insure interaction with the guanidinium ion of arginine of the reacting ion, the introduction of a solvent molecule $\left(\mathrm{ND}_{3}\right)$ appears to facilitate rearrangement, which is subject to an energy barrier of $7.5 \mathrm{kcal}$ $\mathrm{mol}^{-1}$, to achieve bridging between these two functional groups. If the carboxylic acid group is anti rather than syn (as shown in Figure 2), the corresponding transition state cannot be achieved and the energy of the intermediate is about $8 \mathrm{kcal} \mathrm{mol}^{-1}$ higher than that of Complex 2. Following geometric adjustment, the $\mathrm{O}-\mathrm{H}$ bond of the carboxylic acid group is weakened by the strong electrophilic nature of the neighboring guanidinium ion, thereby facilitating proton transfer from the carboxylic acid group to $\mathrm{ND}_{3}$ via TS1.

From TS1, there are two energetically feasible reaction channels: (1) the incipient $\mathrm{ND}_{3} \mathrm{H}^{+}$ion can reversibly transfer a deuteron or proton back to the carboxylic acid group, resulting in a single $\mathrm{H} / \mathrm{D}$ exchange at the C-terminus or (2) $\mathrm{ND}_{3} \mathrm{H}^{+}$in TS1 can undergo a rotation relative to arginine to yield Complex 5. Collision Complex 5 may transfer a proton or deuteron to the adjacent $\mathrm{N}$-terminus via TS2(6), to form a solvent-stabilized zwitterionic Complex 7, which can transfer a proton or deuteron from the $\mathrm{N}$-terminus back to the $\mathrm{C}$-terminus through TS3 (8) to form a non-zwitterionic Complex 9. Upon completing this reaction channel, a single exchange or no net exchange has occurred, depending on whether $\mathrm{ND}_{3}$ or $\mathrm{ND}_{2} \mathrm{H}$ is released from Complex 9 . The apparent site for a single exchange is statistically partitioned between the two termini depending on whether a proton or deuteron is transferred back from the $\mathrm{N}$ terminus to $\mathrm{C}$ - terminus. In addition, if a single exchange occurs and a proton (rather than a deuteron) is transferred back from the $\mathrm{N}$-terminus to C-terminus, then successive collisions can lead to second and third exchanges with $\mathrm{ND}_{3}$.

The detailed potential energy surface illustrates key points that explain why $\mathrm{k}_{1}{ }^{\prime}$ is approximately an order of magnitude greater than $\mathrm{k}_{2}{ }^{\prime}$ and $\mathrm{k}_{3}{ }^{\prime}$. For $\mathrm{H} / \mathrm{D}$ exchange to be initiated at the C-terminus, the complex $\mathrm{ND}_{3} \ldots \mathrm{RH}^{+}$(Complex 2; Figure 2) must be formed. The potential energy surface suggests that if the system overcomes the energy barrier at TS1, a single H/D exchange can occur at the C-terminus. On the other hand, for exchange to occur at the N-terminus the system must sample the entire potential energy surface and overcome barriers imposed by TS2 and TS3. During a single ion-neutral encounter it is unlikely that the collision complex will sample the entire potential energy surface, thus the majority of exchange occurs at the
C-terminus without participation by the N-terminus, thus $\mathrm{k}_{2}{ }^{\prime}$ and $\mathrm{k}_{3}{ }^{\prime}$ are much smaller than $\mathrm{k}_{1}{ }^{\prime}$. Furthermore, reaction channels (1) and (2) can occur without $\mathrm{H} / \mathrm{D}$ exchange, which lowers the reaction efficiencies further.

The H/D exchange mechanism developed for arginine $[\mathrm{M}+\mathrm{H}]^{+}$ions also explains the $\mathrm{H} / \mathrm{D}$ exchange chemistry of di- and tri-arginine containing peptide ions. For example, the energies of the ionic species as well as the energies of various transition states follow the same general trends as observed for arginine $[\mathrm{M}+$ $\mathrm{H}]^{+}$ions; the calculated potential energy surfaces for these ions are available as Supplemental Material. For tripeptide ions, when $\mathrm{ND}_{3}$ approaches the peptide ions, the C-terminus can be positioned near the guanidinium ion and this interaction facilitates C-terminal H/D exchange. In addition, through some geometric rearrangements, the $\mathrm{N}$-terminus can also be positioned in close proximity to the guanidinium ion as well. If such rearrangements are achieved, then $\mathrm{H} / \mathrm{D}$ exchange can involve the hydrogen atoms of both the carboxylic acid group as well as the $\mathrm{N}$ - terminus. Therefore, the maximum number of $\mathrm{H} / \mathrm{D}$ exchanges with measurable rate within the experimental time frame is three (the only exception is RGG, in which the TS2 and TS3 along the potential energy surface are higher in energy than that for GGR and GRG, therefore the corresponding $\mathrm{k}_{2}{ }^{\prime}$ and $\mathrm{k}_{3}{ }^{\prime}$ are much smaller than $\mathrm{k}_{1}{ }^{\prime}$, but close to $\mathrm{k}_{4}{ }^{\prime}$ ).

For dipeptides $[\mathrm{M}+\mathrm{H}]^{+}$ions, the $\mathrm{H} / \mathrm{D}$ exchange reactions are adequately described by the proposed mechanism despite the fact that the exchange chemistry differs significantly from that of arginine and the tripeptides. Such differences can be rationalized in terms of structural differences. For example, the dipeptide ions react by a single exchange with $\mathrm{ND}_{3}$ (Table 1 and Figure 1), and this exchange occurs at the C-terminal carboxylic group, and like arginine and the tri-peptides, the reaction is facilitated by the adjacent guanidinium ion. On the other hand, the lack of conformation flexibility of the peptide backbone makes it difficult to position the N-terminus sufficiently close to the reaction center to allow further exchange reactions to occur, i.e., proton/deuteron shuttling between the $\mathrm{N}$-terminus and the carboxylic acid group is subject to geometric constraints. The difference in the $\mathrm{H} / \mathrm{D}$ exchange reaction for the di-peptides underscores the importance of structures on $\mathrm{H} / \mathrm{D}$ exchange ion-molecule reaction chemistry. That is, the rates and extent of H/D exchange do not simply reflect the number of labile hydrogen atoms present in the molecule; issues related to "solvent accessibility" and structural flexibility also play an important role in the H/D exchange process.

It is worthwhile to compare the mechanism proposed here with Beauchamp's proposed mechanism for $\mathrm{H} / \mathrm{D}$ exchange of glycine oligomer $[\mathrm{M}+\mathrm{Na}]^{+}$ions with $\mathrm{ND}_{3}$ [25a]. Although both models include proton (or deuteron) shuttling between $\mathrm{C}$ - and $\mathrm{N}$-termini of a zwitterionic complex intermediate stabilized by a positive charge site, our mechanism further rationalizes 
why hydrogen atoms of the guanidinium ion are not exchanged. Owing to the large difference in proton affinity of the guanidine group and $\mathrm{ND}_{3}$ the hydrogen atoms of guanidine group are nonlabile, thus the guanidinium ion functions as a localized charge site, which through intramolecular interactions facilitates exchange reactions occurring at the C-terminus. Although not specifically noted by Beauchamp [25a], a similar rationale can be used to explain the exchange reactions of glycine oligomer $[\mathrm{M}+\mathrm{Na}]^{+}$ions with $\mathrm{ND}_{3}$, i.e., $\mathrm{Na}^{+}$is probably bound to the $-\mathrm{COOH}$ group and acts as a localized charge site, which increases the lability of the carboxyl hydrogen, thereby promoting $\mathrm{H} / \mathrm{D}$ exchange with $\mathrm{ND}_{3}$. Both mechanisms can be generalized as follows: $\mathrm{H} / \mathrm{D}$ exchange which occurs at the C-terminus of any peptide with $\mathrm{ND}_{3}$ is the result of a localized charge site near the C-terminus, which increases the acidity of the carboxylic acid and initiates exchange. The mechanism described here is similar to that proposed by Bowers and Wyttenbach [26] and Bowers and Wysocki and coworkers [27] because both mechanisms emphasize the importance of proton shuttling between the $\mathrm{C}$ - and $\mathrm{N}$ - terminus and the formation of a lowenergy "salt-bridge" between the guanidinium ion and C-terminus.

\section{Conclusions}

We propose that the carboxylic acid group plays an important role in gas-phase $\mathrm{H} / \mathrm{D}$ exchange reactions of protonated arginine and arginine-containing di- and tripeptides with $\mathrm{ND}_{3}$. The proposed involvement of the $\mathrm{C}$-terminus in $\mathrm{H} / \mathrm{D}$ exchange is primarily based on the observation that $[\mathrm{M}+\mathrm{H}]^{+}$ions of the methyl ester of arginine do not undergo $\mathrm{H} / \mathrm{D}$ exchange with $\mathrm{ND}_{3}$. For arginine and arginine-containing peptide $[\mathrm{M}+\mathrm{H}]^{+}$ ions, the number and rate of $\mathrm{H} / \mathrm{D}$ exchange depend on the length of peptide chains. For example, three H/D exchanges are observed for $[\mathrm{M}+\mathrm{H}]^{+}$ions of arginine and tripeptides, whereas the dipeptide ions only exchange a single hydrogen atom. To explain these results we develop a general mechanism for H/D exchange. The key feature of this mechanism is that both C- and $\mathrm{N}$-termini must be located in close proximity to the guanidinium ion. Intramolecular interactions between the guanidinium ion and the carboxylic acid group increase the acidity of the C-terminus, which facilitates deprotonation of the $\mathrm{C}$-terminus by $\mathrm{ND}_{3}$. The incipient ammonium ion also functions as a H/D shuttle, resulting in H/D exchange of the hydrogen atoms of the $\mathrm{N}$-terminus (maximal three exchanges via sequential collisions). The H/D exchange reactions of protonated tripeptides are accurately described using a similar mechanism. Although the arginine containing dipeptide $[\mathrm{M}+\mathrm{H}]^{+}$ions also react by $\mathrm{H} / \mathrm{D}$ exchange at the C-terminus, the $\mathrm{N}$-terminal $\mathrm{H} / \mathrm{D}$ exchange reactions are blocked by geometric constraints.

The results of this study underscore the importance of structure, especially intramolecular interactions, on
H/D exchange ion-molecule reaction chemistry. Such interactions affect the efficiency, both kinetics and number of exchanges, of H/D exchange. That is, H/D exchange does not simply reflect the number of labile hydrogen atoms present in the molecule because issues related to "solvent accessibility" and structural flexibility also play an important role in the H/D exchange process.

\section{Acknowledgments}

The authors acknowledge support for this research by the U. S. Department of Energy, Division of Chemical Sciences, BES (DE-FG02-04ER15520), the National Science Foundation (CHE0521216), and The Robert A. Welch Foundation (A-1176). The assistances provided by Dr. Lisa M. Perez (Laboratory for Molecular Simulation, Texas A\&M University) and Jody May are also greatly appreciated.

\section{Appendix A Supplementary Material}

Supplementary material associated with this article may be found in the online version at doi:10.1016/ j.jasms.2009.07.015.

\section{References}

1. Englander, S. W. Hydrogen Exchange and Mass Spectrometry: A Historical Perspective. I. Am. Soc. Mass Spectrom. 2006, 17, 1481-1489.

2. Kjellsson, A.; Sethson, I.; Jonsson, B.-H. Hydrogen Exchange in a Large $29 \mathrm{kD}$ Protein and Characterization of Molten Globule Aggregation by NMR. Biochemistry 2003, 42, 363-374.

3. Deng, Y.; Zhang, Z.; Smith, D. L. Comparison of Continuous and Pulsed Labeling Amide Hydrogen Exchange/Mass Spectrometry for Studies of Protein Dynamics. J. Am. Soc. Mass Spectrom. 1999, 10, 675-684.

4. Weis, D. D.; Wales, T. E.; Engen, J. R.; Hotchko, M.; Eyck, L. F. T. Identification and Characterization of EX1 Kinetics in H/D Exchange Mass Spectrometry by Peak Width Analysis. J. Am. Soc. Mass Spectrom. 2006, 17, 1498-1509.

5. Yan, X.; Deinzer, M. L.; Schimerlik, M. I.; Broderick, D.; Leid, M. E.; Dawson, M. I. Investigation of Ligand Interactions with Human RXR $\alpha$ by Hydrogen/Deuterium Exchange and Mass Spectrometry. J. Am. Soc. Mass Spectrom. 2006, 17, 1510-1517.

6. Cheng, G.; Wysocki, V. H.; Cusanovich, M. A. Local Stability of Rhodobacter capsulatus Cytochrome $c_{2}$ Probed by Solution Phase Hydrogen/Deuterium Exchange and Mass Spectrometry. J. Am. Soc. Mass Spectrom. 2006, 17, 1518-1525.

7. Chitta, R. K.; Rempel, D. L.; Grayson, M. A.; Remsen, E. E.; Gross. M. L. Application of SIMSTEX to Oligomerization of Insulin Analogs and Mutants. J. Am. Soc. Mass Spectrom. 2006, 17, 1526-1534.

8. Dai, S. Y.; Fitzgerald, M. C. Accuracy of SUPREX (Stability of Unpurified Proteins from Rates of H/D Exchange) and MALDI Mass Spectrometry-Derived Protein Unfolding Free Energies Determined Under Non-EX2 Exchange Conditions. J. Am. Soc. Mass Spectrom. 2006, 17, 1535-1542.

9. Abzalimov, R. R.; Kaltashov, I. A. Extraction of Local Hydrogen Exchange Data from HDX CAD MS Measurements by Deconvolution of Isotopic Distributions of Fragment Ions. J. Am. Soc. Mass Spectrom. 2006, $17,543-1551$.

10. Truhlar, S. M. E.; Croy, C. H.; Torpey, J. W.; Koeppe, J. R.; Komives, E. A. Solvent Accessibility of Protein Surfaces by Amide $\mathrm{H} /{ }^{2} \mathrm{H}$ Exchange MALDI-TOF Mass Spectrometry. J. Am. Soc. Mass Spectrom. 2006, 17, 1490-1497.

11. Katta, V.; Chait, B. T. Hydrogen/Deuterium Exchange Electrospray Ionization Mass Spectrometry: A Method for Probing Protein Conformational Changes in Solution. J. Am. Chem. Soc. 1993, 115, 6317-6321.

12. Figueroa, I. D.; Russell, D. H. Matrix-Assisted Laser Desorption Ionization Hydrogen/Deuterium Exchange Studies to Probe Peptide Conformational Changes. J. Am. Soc. Mass Spectrom. 1999, 10, 719-731.

13. Winger, B. E.; Light-Wahl, K. J.; Rockwood, A. L.; Smith, R. D. Probing Qualitative Conformation Differences of Multiply Protonated GasPhase Proteins Via Hydrogen/Deuterium Isotopic Exchange with Water-d2. J. Am. Chem. Soc. 1992, 114, 5897-5898. 
14. Schaaff, T. G.; Stephenson, J. L.; McLuckey, S. A. Gas Phase H/D Exchange Kinetics: DI Versus $\mathrm{D}_{2}$ O. J. Am. Soc. Mass Spectrom. 2000, 11, 167-171.

15. Freitas, M. A.; Marshall, A. G. Rate and Extent of Gas-Phase Hydrogen/ Deuterium Exchange of Bradykinins: Evidence for Peptide Zwitterions in the Gas Phase. Int. J. Mass Spectrom. 1999, 182/183, 221-231.

16. Valentine, S. J.; Clemmer, D. E. Temperature-Dependent H/D Exchange of Compact and Elongated Cytochrome $c$ Ions in the Gas Phase. J. Am. Soc. Mass Spectrom. 2002, 13, 506-517.

17. Valentine, S. J.; Clemmer, D. E. H/D Exchange Levels of ShapeResolved Cytochrome $c$ Conformers in the Gas Phase. J. Am. Chem. Soc. 1997, 119, 3558-3566.

18. Dookeran, N. N.; Harrison, A. G. Gas-phase H-D Exchange Reactions of Protonated Amino Acids and Peptides with $\mathrm{ND}_{3}$. J. Mass Spectrom. 1995, $30,666-674$.

19. Grad, E.; Willard, D.; Bregar, J.; Green, M. K.; Lebrilla, C. B. Site Specificity in the H-D Exchange Reactions of Gas-Phase Protonated Amino Acids with $\mathrm{CH}_{3} \mathrm{OD}$. Org. Mass Spectrom. 1993, 28, 1632-1639.

20. Kovačević, B.; Rožman, M.; Klasinc, L.; Srzić, D.; Maksić, Z. B.; Yáñez, M. Gas-Phase Structure of Protonated Histidine and Histidine Methyl Ester: Combined Experimental Mass Spectrometry and Theoretical ab Initio Study. J. Phys. Chem. A 2005, 109, 8329-8335.

21. Campbell, S.; Rodgers, M. T.; Marzluff, E. M.; Beauchamp, J. L. Deuterium Exchange Reactions as a Probe of Biomolecule Structure. Fundamental Studies of Gas Phase H/D Exchange Reactions of Protonated Glycine Oligomers with $\mathrm{D}_{2} \mathrm{O}, \mathrm{CD}_{3} \mathrm{OD}, \mathrm{CD}_{3} \mathrm{CO}_{2} \mathrm{D}$, and $\mathrm{ND}_{3}$. J. Am. Chem. Soc. 1995, 117, 12840-12854.

22. Lee, S.-W.; Lee, H.-N.; Kim, H.-S.; Beauchamp, J. L. Selective Binding of Crown Ethers to Protonated Peptides Can Be Used to Probe Mechanisms of H/D Exchange and Collision-Induced Dissociation Reactions in the Gas Phase. J. Am. Chem. Soc. 1998, 120, 5800-5805.

23. Linstrom, P. J.; Mallard, W. G. Eds., NIST Chemistry Web Book, NIST Stantdard Reference Database Number 69; June 2005, National Institute of Standard and Technology: Gaithersburg MD, 20889 (http:// webbook.nist.gov)

24. Zhu, C.; Balta, B.; Aviyente, V.; Lifshitz, C. The Interaction of Protonated Diglycine with Ammonia: A Density Functional Theory Model Study. J. Phys. Chem. A 2000, 104, 7061-7067.

25. (a) Cox, H. A.; Julian, R. R.; Lee, S.; Beauchamp, J. L. Gas-Phase H/D Exchange of Sodiated Glycine Oligomers with $\mathrm{ND}_{3}$ : Exchange Kinetics Do Not Reflect Parent Ion Structures. I. Am. Chem. Soc. 2004, 126, 6485-6490; (b) Geller, O.; Lifshitz, C. Gas Phase H/D Exchange of Protonated Arginine Monomers and Dimers. J. Phys. Chem. A 2003, 107, 5654-5659.

26. Wyttenbach, T.; Bowers, M. T. Gas Phase Conformations of Biological Molecules: The Hydrogen/Deuterium Exchange Mechanism. J. Am. Soc. Mass Spectrom. 1999, 10, 9-14.

27. Wyttenbach, T.; Paizs, B.; Barran, P.; Breci, L.; Liu, D.; Suhai, S.; Wysocki, V. H.; Bowers, M. T. The Effect of the Initial Water of Hydration on the Energetics, Structures, and H/D Exchange Mechanism of a Family of Pentapeptides: An Experimental and Theoretical Study. I. Am. Chem. Soc. 2003, 125, 13768-13775.

28. Strittmatter, E. F.; Williams, E. R. Structures of Protonated Arginine Dimer and Bradykinin Investigated by Density Functional Theory: Further Support for Stable Gas-Phase Salt Bridges. J. Phys. Chem. A 2000, 104, 6069-6076.

29. Jockusch, R. A.; Price, W. D.; Williams, E. R. Structure of Cationized Arginine (Arg $\cdot \mathrm{M}^{+}, \mathrm{M}=\mathrm{H}, \mathrm{Li}, \mathrm{Na}, \mathrm{K}, \mathrm{Rb}$, and $\mathrm{Cs}$ ) in the Gas Phase: Further Evidence for Zwitterionic Arginine. J. Phys. Chem. A 1999, 103, 9266-9274.

30. Schnier, P. D.; Price, W. D.; Jockusch, R. A.; Williams, E. R. Blackbody Infrared Radiative Dissociation of Bradykinin and Its Analogues: Energetics, Dynamics, and Evidence for Salt-Bridge Structures in the Gas Phase. J. Am. Chem. Soc. 1996, 118, 7178-7189.

31. Rak, J.; Skurski, P.; Simons, J.; Gutowski, M. Low-Energy Tautomers and Conformers of Neutral and Protonated Arginine. J. Am. Chem. Soc. 2001, 123, 11695-11707.

32. Julian, R. R.; Hodyss, R.; Beauchamp, J. L. Salt Bridge Stabilization of Charged Zwitterionic Arginine Aggregates in the Gas Phase. J. Am. Chem. Soc. 2001, 123, 3577-3583.
33. Price, W. D.; Jockusch, R. A.; Williams, E. R. Is Arginine a Zwitterion in the Gas Phase? J. Am. Chem. Soc. 1997, 119, 11988-11989.

34. Chapo, C. J.; Paul, J. B.; Provencal, R. A.; Roth, K.; Saykally, R. J. Is Arginine Zwitterionic or Neutral in the Gas Phase? Results from IR Cavity Ringdown Spectroscopy. J. Am. Chem. Soc. 1998, 120, $12956-$ 12957.

35. Julian, R. R.; Beauchamp, J. L.; Goddard, W. A. III. Cooperative Salt Bridge Stabilization of Gas-Phase Zwitterions in Neutral Arginine Clusters. J. Phys. Chem. A 2002, 106, 32-34.

36. Kerley, E. L.; Russell, D. H. Mass and Energy Selective Ion Partitioning in a Two-Section Fourier-Transform Ion Cyclotron Resonance Spectrometer Cell. Anal. Chem. 1989, 61, 53-57.

37. Bartmess, J. E.; Georgiadis, R. M. Empirical Method for the Determination of Ion Gauge Sensitivities to Different Gases. Vacuum 1983, 33, 149-153.

38. Chen, L.; Wang, T.-C. L.; Ricca, T. L.; Marshall, A. G. Phase-Modulated Stored Waveform Inverse Fourier Transform Excitation for Trapped Ion Mass Spectrometry. Anal. Chem. 1987, 59, 449-454.

39. (a) Su, T.; Chesnavich, W. J. Parameterization of the Ion-Polar Molecule Collision Rate Constant by Trajectory Calculations. J. Chem. Phys. 1982, 76, 5183-5185; (b) Chesnavich, W. J.; Su, T.; Bowers, M. T. Collisions in a Noncentral Field: A Variational and Trajectory Investigation of Ion-Dipole Capture. J. Chem. Phys. 1980, 72, 2641-2655.

40. Hettick, J. M.; Kashon, M. L.; Simpson, J. P.; Siegel, P. D.; Mazurek, G. H.; Weissman, D. N. Proteomic Profiling of Intact Mycobacteria by MatrixAssisted Laser Desorption/Ionization Time-of-Flight Mass Spectrometry. Anal. Chem. 2004, 76(19), 5769-5776.

41. Reid, G. E.; Simpson, R. J.; O’Hair, R. A. J. A Mass Spectrometric and ab Initio Study of the Pathways for Dehydration of Simple Glycine and Cysteine-Containing Peptide $[\mathrm{M}+\mathrm{H}]^{+}$Ions. J. Am. Soc. Mass Spectrom. 1998, 9(9), 945-956.

42. McLean, J. A.; Ruotolo, B. T.; Gillig, K. J.; Russell, D. H. Ion MobilityMass Spectrometry: A New Paradigm for Proteomics. Int. J. Mass Spectrom. 2005, 240, 301-315.

43. Frisch, M. J.; Gaussian, Inc.: Pittsburgh, PA, 2001.

44. It is important to note that in some areas of the potential energy surface calculations, a specific transition state is not directly associated with the given complex. That is, some geometric rearrangements rotation of ammonia relative to the peptide occurs within the complex before the system experiences the transition state. In some cases, such rearrangements lower the energy of the transition state relative to the complex. In those cases, it is assumed that the transition state is associated with a reactant-like and a product-like complex, both with energy lower than the transition state, but their geometries are unknown. In addition, if the energy barrier is insignificant, the zero point correction can eliminate the energy barrier due to the relatively small size of the basis set.

45. Mason, E. A.; McDaniels, E. W. Transport Properties of Ions in Gases, John Wiley and Sons: New York, 1988; pp. 230-235.

46. Sawyer, H. A.; Marini, J. T.; Stone, E. G.; Ruotolo, B. T.; Gillig, K. J.; Russell, D. H. The Structure of Gas-Phase Bradykinin Fragment 1-5 (RPPGF) Ions: An Ion Mobility Spectrometry and H/D Exchange Ion-Molecule Reaction Chemistry Study. J. Am. Soc. Mass Spectrom. 2005, 16(6), 893-905.

47. Ruotolo, B. T.; Gillig, K. J.; Woods, A. S.; Egan, T. F.; Ugarov, M. V.; Schultz, J. A.; Russell, D. H. Analysis of Phosphorylated Peptides by Ion Mobility-Mass Spectrometry. Anal. Chem. 2004, 76, 6727-6733.

48. Ruotolo, B. T.; Verbeck, I. V., G. F.; Thomson, L. M.; Woods, A. S.; Gillig K. J.; Russell, D. H. Distinguishing Between Phosphorylated and Nonphosphorylated Peptides by Ion Mobility-Mass Spectrometry. J. Proteome Res. 2002, 1, 303-306.

49. Shvartsburg, A. A.; Jarrold, M. F. An Exact Hard-Spheres Scattering Model for the Mobilities of Polyatomic Ions. Chem. Phys. Lett. 1996, 261 86-91.

50. Marini, J. T. Development and Implementation of FT- ICR Mass Spectrometry for the Investigation of Peptide Ion Conformations of Peptide Sequence Isomers Containing Basic Amino Acid Residues by Gas-Phase Hydrogen/Deuterium Exchange; Ph. D. Dissertation, Texas A and M University: College Station, TX, 2003 